\title{
Promoting vasectomy services in Malawi
}

\author{
Brian Perry \\ Catherine Packer \\ Dawn S. Chin-Quee \\ Trinity Zan \\ Dominick Shattuck
}

Follow this and additional works at: https://knowledgecommons.popcouncil.org/departments_sbsr-rh How does access to this work benefit you? Let us know!

\section{Recommended Citation}

Perry, Brian, Catherine Packer, Dawn S. Chin-Quee, Trinity Zan, and Dominick Shattuck. 2016. "Promoting vasectomy services in Malawi." Durham, NC: FHI 360 and Washington, DC: The Population Council, The Evidence Project. 


\section{PROMOTING VASECTOMY SERVICES IN MALAWI}

The Family Planning 2020 (FP2020) movement began in 2012, when more than 150 political leaders at the London Summit on Family Planning committed to provide 120 million women in the world's poorest countries with access to contraceptives by 2020 . FP2020 aims to support the reproductive rights of women and girls and empower them to achieve their reproductive goals. This is done, in part, by ensuring FP clients across the globe are provided with the informed choice of a wide range of high quality contraceptive methods. Initiatives designed to increase contraceptive use have typically focused on female uptake of services, as evidenced from the commitment of the Malawi Government to increase the modern contraceptive prevalence rate (mCPR) among all women to $60 \%$ by $2020 .{ }^{1}$ Malawi has made great progress in reaching this goal, and a significant proportion of the CPR is use of permanent methods (mostly female sterilization). In 2015, Malawi's Ministry of Health launched the Malawi Family Planning Costed Implementation Plan, 20162020, which outlines key interventions and cost information to further increase the CPR. ${ }^{1}$ Expanding the method mix - by increasing capacity of vasectomy services, addressing cultural, religious and community barriers to male FP involvement, and creating male-friendly FP services - can increase $\mathrm{mCPR}^{2}$ beyond targets focusing on women only and help Malawi progress towards its FP goals.

However, the current range of accessible FP methods, behavior change messaging and interpersonal communication reinforce the notion that FP services are specifically for women. Pervasive misconceptions about vasectomy constrain financial, policy and community support for the method. As a result, men are insufficiently engaged in reproductive health services and women carry the primary responsibility for using contraception.

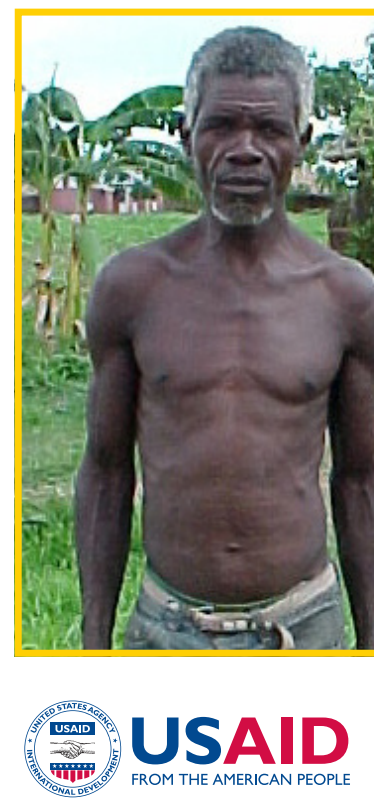

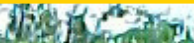

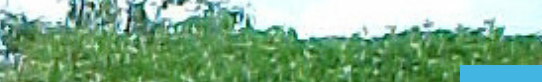

The truth is vasectomy services provide couples seeking to limit family size with a highly effective, permanent, and malefocused FP alternative without side effects.

No-scalpel vasectomy:

- Is PAINLESS, FAST, and EXTREMELY EFFECTIVE

- Requires LITTLE RECOVERY TIME,

- Has ECONOMIC AND HEALTH BENEFITS for the family,

- Has NO SIDE EFFECTS, and

- DOES NOT INTERFERE WITH SEXUAL FUNCTION OR PLEASURE.

Greater education and support for vasectomy at a national level would address the gender imbalance in contraceptive availability and use. Unlike a new female-focused method, meaningful integration of vasectomy into a method mix expands the reproductive health paradigm to include men as users of FP services and promotes couples' fertility as a shared responsibility. This more holistic approach to reproductive health supports an informed choice of a wide range of high quality contraceptive methods.

Vasectomy is the most cost-effective and safest permanent method for meeting the needs of men and women who desire to limit future births (i.e. want no more children). Given the significant increases in use of modern contraception and Malawi's commitment to increasing coverage of FP services and encouraging community participation, now is an opportune time to invest in vasectomy services. By promoting and supporting the voluntary use of vasectomy as part of the overall method mix, Malawi can help meet its national and international FP commitments and contribute to the development of a more gender equitable society, where men play a supportive and proactive role in their families' health.

\section{Greater integration of vasectomy}

promotion and services is a first step in expanding the reproductive health paradigm to include men not just as default partners of female clients, but as equal beneficiaries of reproductive health programs. 


\section{VASECTOMY HELPS INDIVIDUALS AND COUPLES ACHIEVE THEIR DESIRED FAMILY SIZE}

In Malawi, a high percentage of married women (37\%) and an even higher percentage of married men (45\%) of reproductive age reported a desire to limit future births. ${ }^{3}$ Older men and women were far more likely to want to limit births ( $88 \%$ of these men and $68 \%$ of these women were at least 30 years old) though a substantial number of younger people are also interested in limiting family size.

Estimated Market Size for Permanent Methods in Malawi, 20203,4

\begin{tabular}{|l|l|l|r}
\hline Total Female Population & $10,117,439$ & $10,086,489$ & Total Male Population \\
\hline Married (15 - 49 years old) & $\mathbf{2 , 8 0 8 , 4 5 1}$ & $\mathbf{2 , 6 1 9 , 3 3 1}$ & Married (15 - 54 years old) \\
\hline Desire to Limit Future Births* & $\mathbf{1 , 0 3 5 , 7 3 7}$ & $\mathbf{1 , 1 3 5 , 8 1 8}$ & Desire to Limit Future Births*
\end{tabular}

*Excludes men and women who report prior sterilization or infecundity

\section{VASECTOMY EXPANDS THE CHOICE FOR EFFECTIVE PERMANENT METHODS OF CONTRACEPTION}

Over $77 \%$ of married women who reported a desire to limit future births in Malawi were using either short-term contraceptive methods or no method at all. ${ }^{3}$ Though roughly a fifth of these women are already using permanent methods, nearly all are female sterilization - a more invasive sterilization procedure than vasectomy. Injectables, which have a high rate of discontinuation due to side effects, represent over $40 \%$ of the contraceptives used by this population. Vasectomy offers a lifetime of contraceptive protection without fear of side effects.
Contraceptive Use among Married Women (15-49) who want to Limit Future Births in Malawi ${ }^{3}$

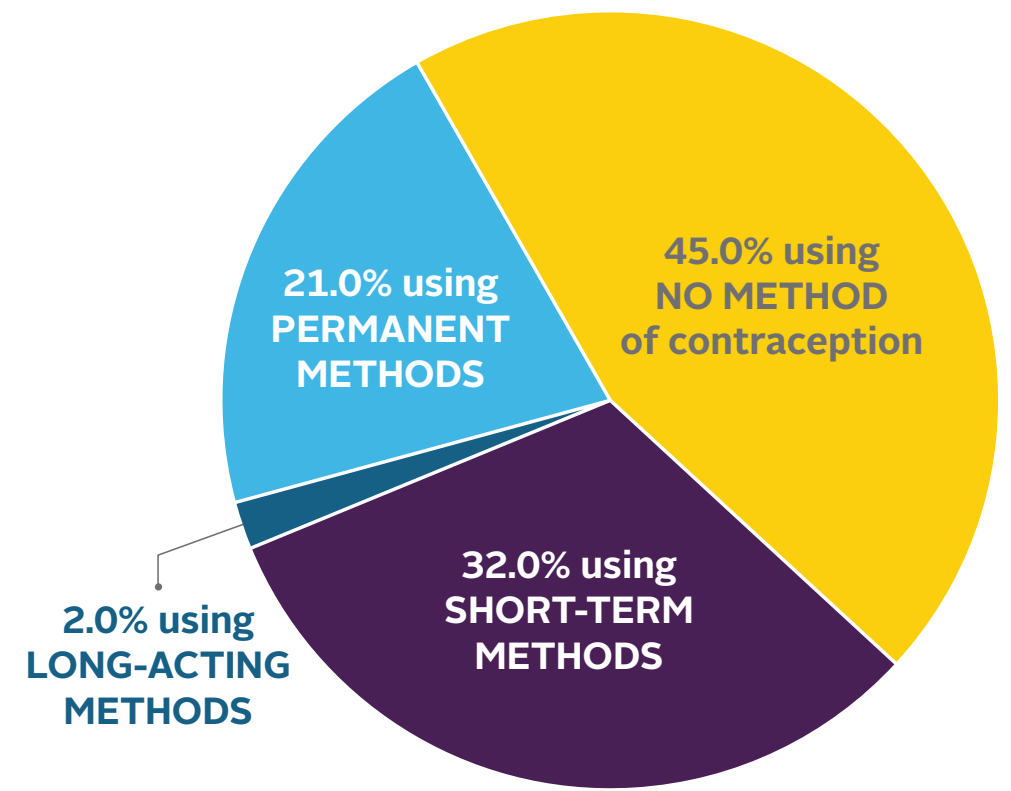

Unmet Need for Limiting:

Couples who want to limit future births and are currently using short-term or no method of contraception are an important potential market for vasectomy services.

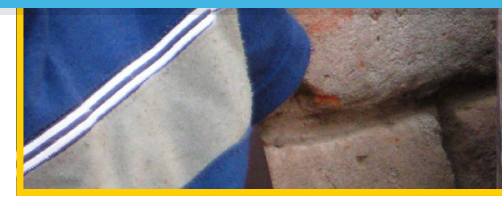
(16) 
If Malawi were to achieve its goal of increasing the mCPR to $60 \%$ among all women (15-49) by 2020 , there would be an estimated 2.8 million total contraceptive users in this demographic. If a small percentage of unmet need for limiting among married couples in Malawi were satisfied through greater uptake of vasectomy, it would have a direct and lasting impact on public health and reduce the overall costs of FP commodities and services.

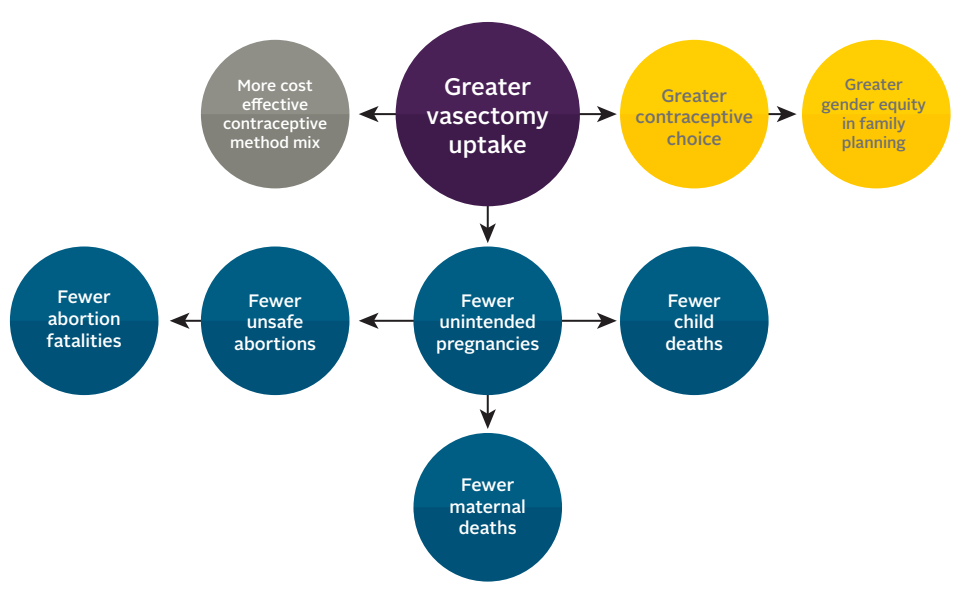

\section{VASECTOMY IS AMONG THE MOST COST-EFFECTIVE FAMILY PLANNING METHODS}

Vasectomy is less expensive per CYPa than all other forms of contraceptives presently provided, with the exception of copper IUDs., 6 In Malawi, increased investment in vasectomy would result in greater savings per CYP in commodity and service costs of the nation's contraceptive method mix.

\section{Cost of Contraceptive Provision per CYP in Malawi, $2015^{5,6}$}

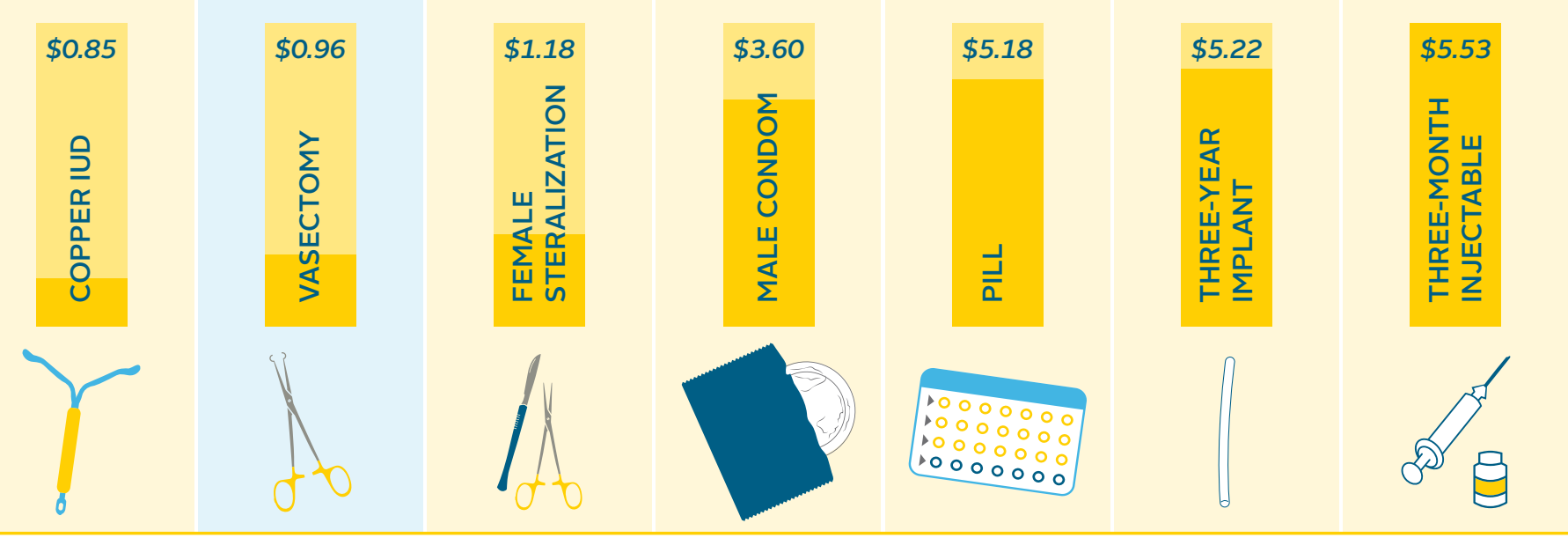

Costs per CYP only reflect direct labor and costs of commodities and consumable supplies and does not take into account other potential costs associated with introducing vasectomy into the market, including demand creation, additional provider trainings or expansion of service coverage.

\section{VASECTOMY CAN CONTRIBUTE TO A LESS EXPENSIVE AND MORE EFFECTIVE METHOD MIX}

For example, if by 2020 , only $5 \%$ of married women (30 to 49) who desire to limit births were to switch from using short-term methods to relying on their partner's vasectomy to achieve their fertility goals, it would improve the cost effectiveness of the method mix for this demographic by $14 \%$.

This marginal increase in the use of vasectomy for limiting births - equal to 48,242 vasectomies performed over the next 5 years - would improve the public health impact of the method mix by over $15 \%$.

${ }^{b}$ Original projections calculated by FHI 360 in 2016.

\section{CUMULATIVE COST-EFFECTIVENESS AND PUBLIC HEALTH IMPACTS (2016-2020) ${ }^{\text {b }}$}

\begin{tabular}{|r|c|c|}
\hline Cost per CYP & $\begin{array}{c}\text { Current } \\
\text { Method Mi** }\end{array}$ & $\begin{array}{c}\text { Method Mix* } \\
\text { including 5\% } \\
\text { vasectomy CPR }\end{array}$ \\
\hline Total CYP & $2,241,914$ & $2,585,749$ \\
\hline Unintended pregnancies & 645,671 & 744,696 \\
\hline averted & 4,358 & 5,027 \\
\hline Maternal deaths averted & 42,614 & 49,150 \\
\hline Unsant deaths averted & 192,152 & 221,621 \\
\hline Abortion case-fatalities & 999 & 1,152 \\
averted & 9996 & \\
\hline & &
\end{tabular}

* Among married women (30-49) who want to limit births 
The recommendations below, adapted from a recent document review ${ }^{7,8}$, may aid policymakers and program implementers in Malawi to increase demand for and supply of vasectomy services and to create a greater enabling environment for a male-inclusive FP agenda.

\section{CREATE AN ENABLING ENVIRONMENT:}

- To close the gap between FP commitments and available financial support, donors and the government should invest in the most cost-effective method mix to address the changing needs of men, women, and couples over their reproductive lives.

- Address gender-related norms that may negatively impact FP decision-making, by empowering women and couples to talk openly about their reproductive intentions and consider vasectomy as a desirable way to ensure the family's health and well-being.

- Include vasectomy in sexual and reproductive health education for youth, particularly for young men, to begin early sensitization on vasectomy as a viable form of limiting births in the future. Explore use of social media to engage young people in obtaining information.

- Create "male-friendly" reproductive health services, For example, train male health workers to counsel men about their FP options.

\section{INCREASE SUPPLY OF VASECTOMY SERVICES:}

- Focus on initial public-sector capacity building in locations with available teaching medical facilities, existing privatesector vasectomy services and ample demand to sustain skill development.

- $\quad$ Address negative provider biases and attitudes about providing vasectomy services through education and provider testimonials, and ensure providers receive adequate compensation for services.

- Build capacity in hospitals and health centers to offer no-scalpel vasectomy with use of fascial interposition and thermal cautery.

- Invest in sustainable vasectomy skill development by training certified public-sector vasectomy providers as vasectomy trainers.

\section{ENCOURAGE DEMAND FOR VASECTOMY:}

- Conduct formative assessments to understand misconceptions toward, as well as cultural, religious and community barriers to vasectomy use.

- Engage and support vasectomy "champions" among religious, political and community leaders, health providers and satisfied vasectomy clients.

- Disseminate accurate information about vasectomy; particularly in regard to method safety and its effect on virility and physical strength.

- Build on the relatively high prevalence of female sterilization, and educate men and women on the advantages of vasectomy compared to tubal ligation.

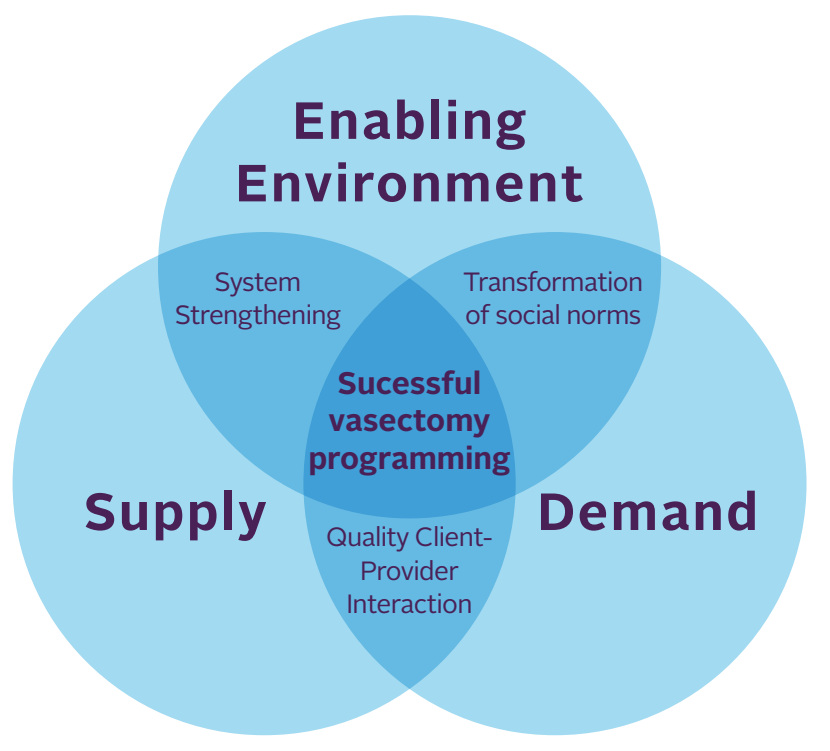

Adapted from EngenderHealth's Supply-Enabling Environment-Demand (SEED) Programming Model ${ }^{\mathrm{TM}}$

Government of Malawi. Malawi Costed Implementation Plan for Family Planning, 2016-2020. 2015.

Available at: http://www.healthpolicyproject.com/ns/docs/Malawi_CIP_FINAL.pdf

Ross J and Stover J. Use of modern contraception increases when more methods become available: analysis of evidence from 1982-2009. Glob Health Sci Pract. 2013;1(2):203-212.

National Statistical Office [Malawi] and ICF International. 2011. Malawi Demographic and Health Survey 2010. MWIR61FL.SAV and MWMR61FL.SAV. Zomba, Malawi and Calverton, Maryland: National Statistical Office and ICF Macro [Producers]. ICF Macro [Distributor], 2011.

US Census Bureau. International Database. Last updated July 2015. Available at http://www.census.gov/population/international/data/idb/informationGateway.php.

Tumlinson K, Steiner MJ, Rademacher KH, Olawo A, Solomon M, and Bratt J. 2011. The promise of affordable implants: is cost recovery possible in Kenya. Contraception, 83:88-93.

Rademacher KH, Solomon M, Pascual C, Njunguru J, Brett T, and Steiner MJ. 2016. Expanding access to a new, more affordable levonorgestrel intrauterine system in Kenya: Perspectives from Key Opinion Leaders. Global Health: Science and Practice. In press.

Perry B, Packer C, Chin Quee D, Zan T, Dulli L, and Shattuck D. Recent experience and lessons learned in vasectomy programming in low-resource settings: a document review. Durham, NC: FHI 360 and Washington, DC: Population Council, the Evidence Project. 2016.

8 Packer C, Perry B, Chin-Quee D, Zan T, and Shattuck D. How to create successful vasectomy programs. Durham, NC: FHI 360 and Washington, DC: The Population Council, The Evidence Project. 2016 


\section{THE EVIDENCE PROJECT}

\section{POPULATION COUNCIL}

4301 Connecticut Avenue, NW, Suite 280

Washington, DC 20008 USA

Tel +1202 2379400

Evidenceproject.popcouncil.org

This work is made possible by the generous support of the American people through the

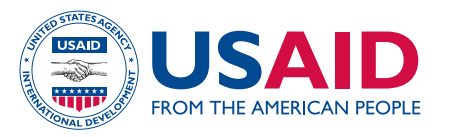

United States Agency for International Development (USAID) under the terms of The

Evidence Project, co-operative agreement no. AID-OAA-A-13-00087. The findings and conclusions are the sole responsibility of the authors and do not necessarily reflect the views of USAID or the United States Government.

The Evidence Project seeks to expand access to high quality family planning/ reproductive health services worldwide through implementation science, including the strategic generation, translation, and use of new and existing evidence. The project is led by the Population Council in partnership with the INDEPTH Network, the International Planned Parenthood Federation, PATH, and the Population Reference Bureau.

FHI 360 is a nonprofit human development organization dedicated to improving lives in lasting ways by advancing integrated, locally driven solutions. Our staff includes experts in health, education, nutrition, environment, economic development, civil society, gender, youth, research and technology - creating a unique mix of capabilities to address today's interrelated development challenges. FHI 360 serves more than 60 countries, all 50 U.S. states and all U.S. territories.

For more information about vasectomy programmatic recommendations, contact:

FHI 360

Mailing address:

359 Blackwell Street,

Suite 200, Durham, NC 27701

Telephone: +19195447040

Fax: +19195447261

Published in March 2016

Suggested Citation:

Perry B, Packer C, Chin-Quee D, Zan T, and Shattuck D. Promoting Vasectomy Services in Malawi.

Durham, NC: FHI 360 and Washington, DC: The Population Council, the Evidence Project. 2016.

Copyright (c) $2016 \mathrm{FHI} 360$. All rights reserved. 


\section{PHOTO CITATIONS}

Photo 1 - ID: 1515-353

A family in Mulange, Malawi.

(C) 2000 Arturo Sanabria, Courtesy of Photoshare
Photo 2 - ID: 7006-6

Home-based care providers in Salima, Malawi, assess the needs of their clients.

(c) 2010 Sally Zweimueller, Courtesy of Photoshare 